\title{
Flexural Toughness Measurements on High-Strength Steel Fiber-Reinforced Concrete
}

\author{
Farhad Reza ${ }^{*}$ \\ ${ }^{1}$ Department of Mechanical \& Civil Engineering, Minnesota State University, Mankato, Minnesota, United \\ States \\ Email: farhad.reza@mnsu.edu
}

\begin{abstract}
High-strength concrete is useful for a number of applications in construction. One drawback of the material is its relatively high brittleness which can lead to sudden and catastrophic failure. A potential improvement in ductility could be achieved by incorporating fiber reinforcement In this paper, results from an experimental program to characterize flexural strength and flexural toughness for high strength concrete with compressive strength of $103 \mathrm{MPa}$ (15,000 psi) reinforced with steel fibers are presented. Three different techniques for measuring deflection and controlling the experiments were utilized including crack mouth opening displacement control, ram control, and load-point control. Toughness indexes were evaluated according to ASTM C1018, and Japan Society of Civil Engineers (JSCE) standard test methods for measuring flexural toughness of fiber-reinforced concrete. Two types of fibers, namely hooked-end and crimped fibers were investigated. Three different fiber volume percentages were utilized, namely $0.5 \%, 1.0 \%$ and $1.5 \%$. The JSCE toughness index was highly sensitive to fiber volume, while the I5 toughness index and flexural strength were also sensitive but to a lesser extent. Notch sensitivity or size effect appeared to exist for flexural strength, and hooked-end fibers provided higher flexural strength than crimped fibers.
\end{abstract}

Keywords: Fracture toughness, fiber-reinforcement, bending strength, mechanical properties, highstrength concrete.

\section{Introduction}

High-strength concrete can provide multiple benefits for applications in mainstream construction. A major drawback of the material is that it tends to be brittle. Brittle failures are undesirable because they can be catastrophic and occur without warning. One possible mechanism for enhancing the ductility of high strength concrete may be the addition of steel fibers. It has been reported that steel fibers help to improve the ductility of concrete under all modes of loading [1]. The improvements in ductility depend on the type and volume of fibers. Ductility can be provided by discrete fibers bridging cracks before being pulled out. Fibers with enhanced resistance to pullout are fabricated with a crimped or wavy profile, surface deformations, or improved end anchorage provided by hooking, teeing or end enlargement. Flexural strength increases are greater than in tension or compression because ductile behavior of the steel fiber-reinforced concrete (SFRC) on the tension side of a beam alters the normally elastic distribution of stress and strain over the depth. The altered stress distribution is essentially plastic in the tension zone and elastic in the compression zone thus shifting the neutral axis towards the compression side. Perhaps the most beneficial improvement from the addition of fibers is the increase in energy absorption capacity which can be quantified by the flexural toughness of the composite.

There are many different measurement techniques and indexes for characterizing flexural toughness of fiber-reinforced concrete. An overview of several available methods is presented in reference 2 [2]. Perhaps the most common method of measuring flexural toughness has been the ASTM C1018 [3] method for measuring flexural toughness using simple beam with third-point loading under deflection control. The flexural strength of the composite may also be obtained during this test; however, the values may differ from the result obtained by the load-controlled procedure of ASTM C78 [4]. Some criticisms of the ASTM C1018 were that is was necessary to measure the deflection at first crack very accurately and there may be a size effect. For this reason, ASTM C1018 was withdrawn and replaced 
with ASTM C1609 [5] in 2005. An outline of the basic concepts involved in the ASTM C1018, ASTM C1609, and Japan Society of Civil Engineers (JSCE) [6] methods of measuring flexural toughness is presented further on in this paper. More detailed explanations can be found in other references [7-10].

Results from a round-robin testing program conducted at six different universities for the flexural toughness of normal-strength $(28-41 \mathrm{MPa})$ SFRC have been published [11]. The reference also discusses the amount of variability that can exist in reported data due to different techniques for measurement of deflection. In addition, the reference contains discussion on the use of crack mouth opening displacement (CMOD) techniques in lieu of deflection measurements for toughness characterization.

In another study, another technique for flexural toughness measurements of fiber-reinforced concrete called the residual strength testing method is described [12]. In this method, a stable narrow crack is first created in the beam by loading it in parallel with a steel plate. Next the plate is removed and the specimen is reloaded to obtain the post-crack load displacement response, which reveals the residual strength of the material.

A study comparing the mechanical properties of concrete made with different types of steel fibers is described in reference 13 [13]. It was found that at an aspect ratio of 60 and for a fiber volume fraction of $2 \%$, hooked fibers generated flexural strengths and energy absorption capacities higher than those of straight and crimped fibers.

Although there is a substantial amount of literature regarding the flexural properties of fiberreinforced concrete, there is relatively limited amount of data available for high-strength concretes with steel fiber reinforcement. The results from flexural tests on SFRC with compressive strengths of up to 82 MPa have been reported [14]. It was concluded that toughness indexes at larger deflections, for example $\mathrm{I}_{100}$ should be used rather than $\mathrm{I}_{5}$ or $\mathrm{I}_{10}$. It was also found that hooked-end fibers were very effective in improving toughness. Another paper presents results from 10 beam tests, most of which contained longitudinal steel reinforcement as well as shear reinforcement [15]. The compressive strengths of the SFRC varied between 72-95 MPa. It was concluded that steel fibers improved flexural rigidity of beams before the yield stage and increased the displacement at failure.

In this paper, the results of flexural toughness measurements on high-strength (56-day compressive strength of $103 \mathrm{MPa}$ or $15000 \mathrm{psi}$ ) SFRC beams are presented. Two different specimen sizes including both notched and unnotched beams were investigated. Two different types of steel fibers (hooked-end and crimped) were employed. Three different volume percentages of fibers were used namely $0.5 \%, 1.0 \%$ and $1.5 \%$.

\section{$2 \quad$ Flexural Toughness Indexes}

One possibility for characterizing the toughness of steel fiber-reinforced concrete would require obtaining complete load-deflection curves of two beams - one unreinforced and the other made from an identical mix without the steel fibers. The ratio of the area under the load-deflection curve until the load reaches zero for the fiber composite divided by the area for its unreinforced counterpart would define the toughness index, $\mathrm{I}_{\mathrm{t}}$. While this method is technically sound, it is not practical because of the difficulty in obtaining identical plain concrete beams, and also because it may require very large deflections to obtain a load of zero. For this reason, toughness indexes based on a single load-deflection curve of the fiberreinforced concrete beam are more popular. In this paper, indexes based on three different methods were utilized namely, ASTM C1018, JSCE and CMOD on notched beams.

\subsection{ASTM C1018 Toughness Indexes}

The test method consists of testing a simply supported beam under third-point loading. Deflections can be monitored either at the midspan or the load-point locations. The concept behind the indexes can be illustrated by referring to the schematic load-deflection curve for SFRC in Fig. 1. 


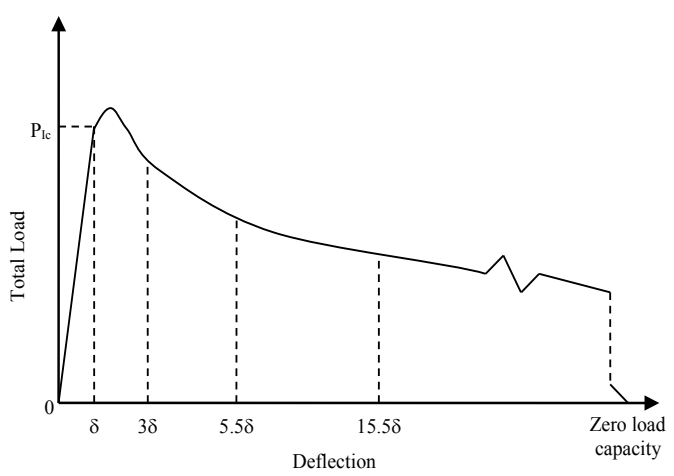

Figure 1. Schematic load vs. deflection curve for fiber-reinforced concrete beam used to define ASTM C1018 toughness indexes.

The first crack is assumed to occur at the point where the load-deflection curve becomes nonlinear. The area under the load-deflection curve until the first-crack deflection is calculated. Thereafter, the area under the load-deflection curve at various multiples of the first-crack deflection is obtained. For example, the definitions of the indexes $\mathrm{I}_{5}, \mathrm{I}_{10}, \mathrm{I}_{20}$ and $\mathrm{I}_{30}$ are given by equations 1 through 4 .

$$
\begin{gathered}
I_{5}=\frac{\text { Area up to } 3 \delta}{\text { Area up to } \delta} \\
I_{10}=\frac{\text { Area up to } 5.5 \delta}{\text { Area up to } \delta} \\
I_{20}=\frac{\text { Area up to } 10.5 \delta}{\text { Area up to } \delta} \\
I_{30}=\frac{\text { Area up to } 15.5 \delta}{\text { Area up to } \delta}
\end{gathered}
$$

The reference case for the definition of the indexes is that of elastic-perfectly plastic behavior as depicted in Fig. 2. For example, the area up to $\delta$ would be $0.5 \mathrm{P}_{c} \delta$. The area up to $3 \delta$ would be $2.5 \mathrm{P}_{c} \delta$. Hence the $\mathrm{I}_{5}$ value would be 5 times the area up to the first crack if the material behaved in an elasticperfectly plastic manner. The $\mathrm{I}_{10}$ value would be 10 times the area up to the first crack and so on. Further information about the behavior of the composite can be gleaned by comparing the ratio of indexes, for example $\mathrm{I}_{10} / \mathrm{I}_{5}$. For an elastic-perfectly brittle material the ratio would equal 1 . Thus, the ratio for SFRC with a steep descending branch tends to be 1 .

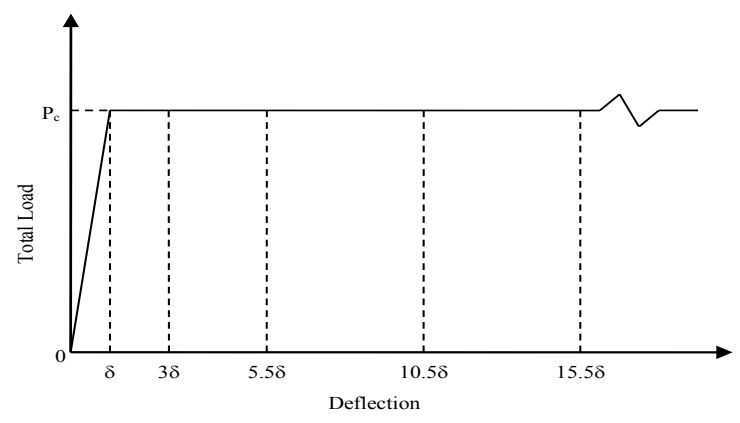

Figure 2. Schematic load vs. deflection curve for a beam of an elastic-perfectly plastic material.

\section{$2.2 \quad$ ASTM C1609 Toughness Index}

In this method, load and net deflection are monitored and recorded to an end-point deflection of at least 1/150 of the span. On the curve, first-peak, peak, and residual loads at specified deflections are 
identified and are used to calculate flexural performance parameters toughness $\left(\mathrm{T}^{\mathrm{D}}{ }_{150}\right)$ and Equivalent Flexural Strength Ratio $\left(\mathrm{R}_{\mathrm{T}, 150}^{\mathrm{D}}\right)$, where $\mathrm{D}$ is nominal depth of the beam specimen in mm (see Fig. 3 ).

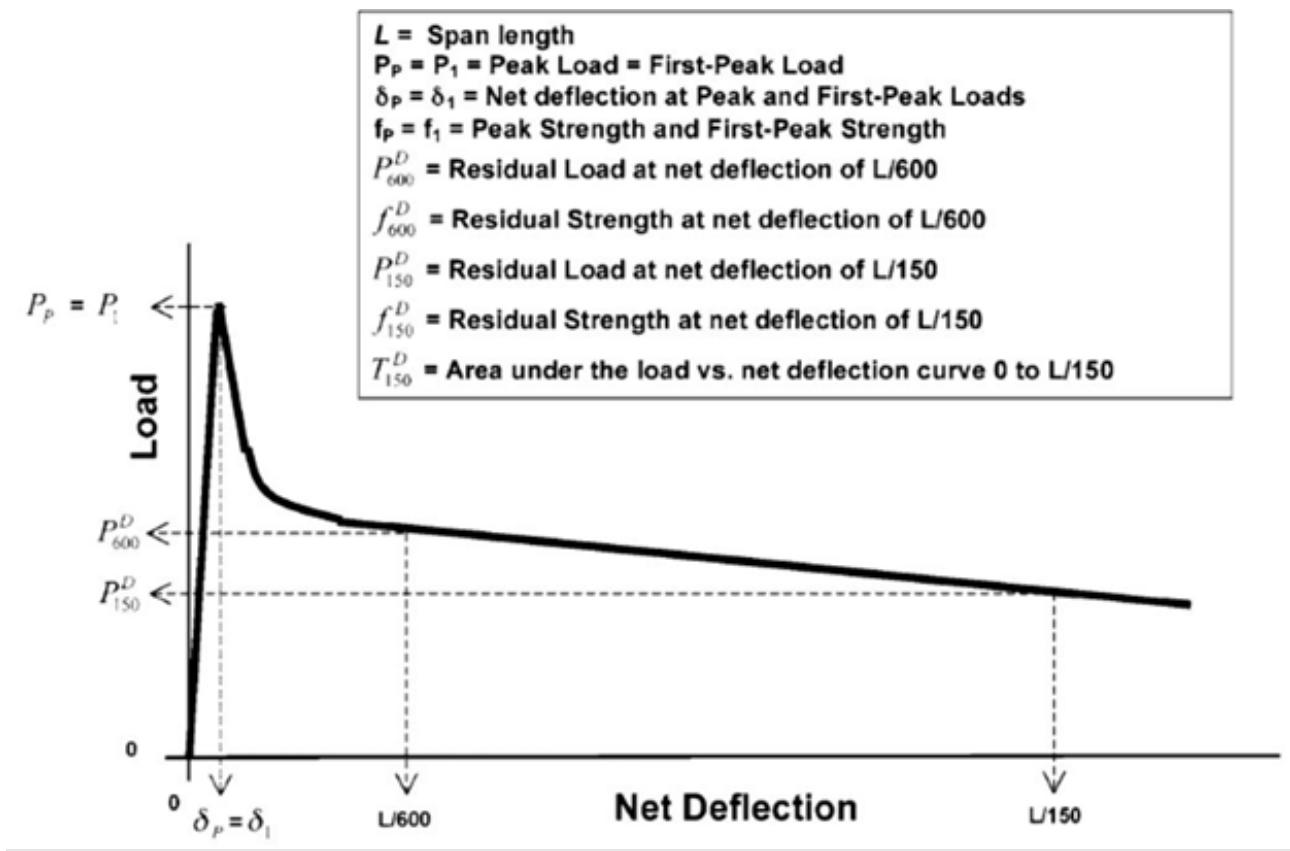

Figure 3. Schematic load vs. deflection curve for ASTM C1609 parameters.

\section{$2.3 \quad$ JSCE Toughness Index}

The method for evaluating toughness suggested by JSCE involves determining the energy required to deflect the beam a specified amount. The index $\mathrm{T}_{\mathrm{b}}$ is defined as the area under the load-deflection curve up to a deflection of $1 / 150$ of the span length. If the specimen fails before reaching the specified deformation, the area immediately before failure is considered.

\subsection{CMOD Toughness Indexes}

The techniques using crack mouth opening displacement are similar to those described in ASTM C1018, except that load-CMOD curves are obtained rather than load-deflection curves. Some of the advantages are: (a) the toughness index can be readily related to the fundamental fracture and crack propagation characteristics of the composite; (b) CMOD can be readily related to crack-width levels; (c) CMOD measurements are less prone to errors than the deflection measurements [11]; and (d) CMOD control can provide the most stable post-crack response. One disadvantage is that since notched beams must be employed, the calculated flexural toughness may be notch-sensitive. Load-CMOD plots can be used to identify the CMOD at first crack. Toughness values can then be non-dimensionalized using the energy required to create the first crack. For example, the toughness at five times the first-crack CMOD can be obtained using equation 5 .

$$
I_{C M O D 5}=\frac{\text { Energy required for opening CMOD by } 5 \text { times the CMOD at first crack }}{\text { Energy required for the initiation of crack }}
$$

\section{$3 \quad$ Experimental Program}

A total of 41 unnotched and 21 notched beams were tested. The beams were all moist cured in $95 \%$ relative humidity environment. The age at testing was between $56-62$ days. Two different types of 
steel fiber were utilized namely, crimped fiber (shown in Fig. 4) and hooked-end fiber (shown in Fig. 5). Both fibers had lengths of $51 \mathrm{~mm}$ and Modulus of Elasticity of $200 \mathrm{GPa}$. The crimped fiber had an aspect ratio of 50 and a tensile strength of $1.14 \mathrm{GPa}$. The hooked-end fiber had an aspect ratio of 100 and a tensile strength of $1.17 \mathrm{GPa}$.

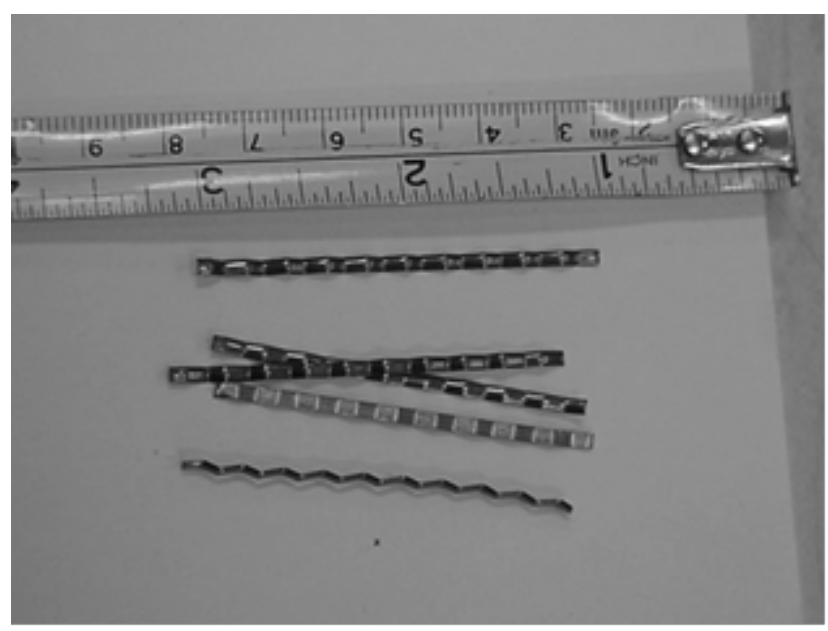

Figure 4. Crimped steel fibers.

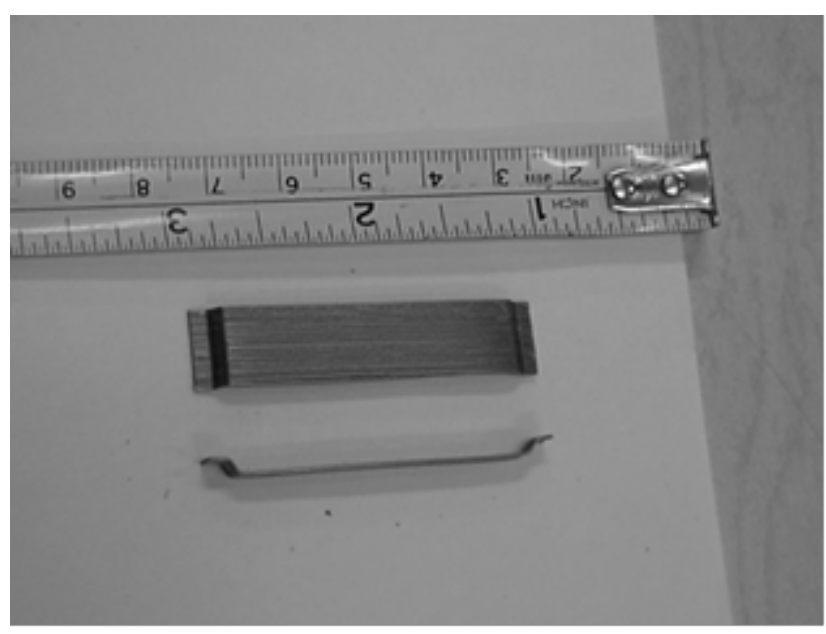

Figure 5. Hooked-end steel fibers.

Table 1. Mixture Proportions for High-Strength Steel Fiber-Reinforced Concrete.

\begin{tabular}{ccc}
\hline Constituent & $\begin{array}{c}\text { Content per unit volume } \\
\left(\mathrm{kg} / \mathrm{m}^{3}\right)\end{array}$ & $\begin{array}{c}\text { Weight ratio to total cementitious } \\
\text { material }\end{array}$ \\
\hline Type III cement & 328 & 0.55 \\
Silica fume & 101 & 0.20 \\
Class C Fly ash & 76 & 0.15 \\
Water & 111 & 0.22 \\
Coarse aggregate & 997 & 1.98 \\
Sand & 537 & 0.63 \\
High-range water & 23 liter $/ \mathrm{m}^{3}$ of concrete & $\mathrm{NA}$ \\
reducer &
\end{tabular}


The fiber volume percentages varied between $0.5 \%, 1 \%$ and $1.5 \%$. The proportions used for the base concrete mixture are listed in Table 1. Type III portland cement was used together with silica fume and Class C fly ash. The coarse aggregate was trap rock with $9.5 \mathrm{~mm}$ (3/8 inch) maximum aggregate size. The fine aggregate was natural sand with fineness modulus of about 2.4 . The high-range water reducing admixture conformed to ASTM C-494 Type A and F.

For compressive strength testing, cylinders of $152 \mathrm{~mm}$ (6 inch) diameter and $305 \mathrm{~mm}$ (12 inch) length were used. Compressive strengths were obtained at 7, 14, 28 and 56 days with a total of 21 specimens tested at each age. Moist curing was employed. The 21 specimens at each age included three plain concrete specimens and three each of hooked and crimped fiber for $0.5,1$ and 1.5 volume percentages. No statistically significant difference in compressive strength based on volume percentage of fibers or type of fibers was detected; however, in general the plain concrete specimens tended to give the largest values of compressive strength. Figure 6 shows the change in compressive strength for the average of the 21 specimens at each age as a function of curing time.

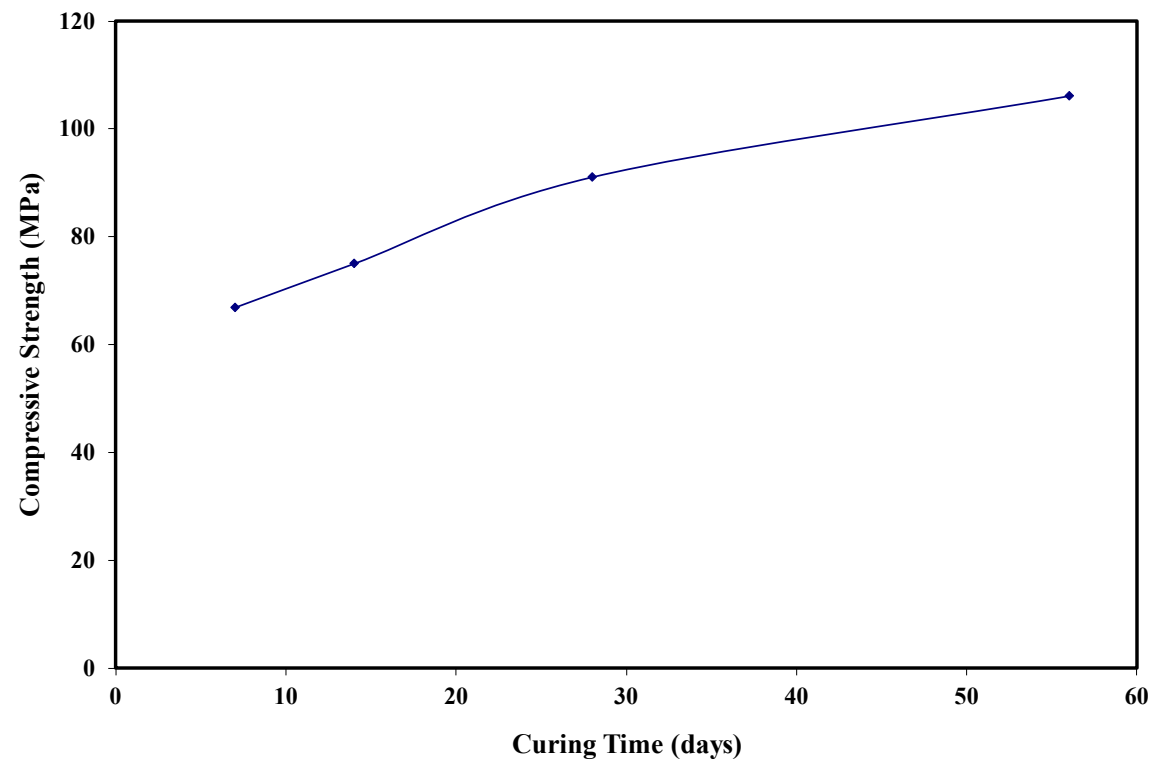

Figure 6. Compressive strength of high-strength steel fiber-reinforced concrete. Average of 21 specimens at each curing age.

Two different sizes of prismatic beams were utilized. The smaller beams had width- depth-length proportions of $152 \times 152 \times 610 \mathrm{~mm}$ ( 6 × 6 × 24 in.) The notched version of this beam was created by inserting a removable piece of plastic in the mold so that the notch depth was $38 \mathrm{~mm}(1.5 \mathrm{in}$.) and the thickness was $6.35 \mathrm{~mm}$ (1/4 in.) The tested span length was $457 \mathrm{~mm}$ (18 in.) The larger beams were 152 x 229 x $914 \mathrm{~mm}(6 \times 9 \times 36$ in.) The notch in the larger beams was $57 \mathrm{~mm}$ (2.25 in.) deep and $6.35 \mathrm{~mm}$ (1/4 in.) thick. The span length was $686 \mathrm{~mm}$ (27 in.). For both sizes of notched beams, the ratio of notch depth to uncracked ligament depth was 0.25 . The beams were larger than the commonly used 100 x 100 × $350 \mathrm{~mm}$ ( 4 × 4 x 14 in.) prisms and followed the recommendation of reference 8 [8] to keep the depth at least three times the length of the fiber to reduce preferential fiber alignment. The beams were cast on their sides, that is, concrete was poured perpendicular to the depth dimension. The specimens were vibrated internally to ensure proper consolidation.

The testing was performed on a $500 \mathrm{kN}$ (112 kip) Instron closed loop control servohydraulic test frame. Load was applied to the concrete beam via a rigid steel beam with adjustable length roller supports. At the bottom, the concrete beam also rested on roller supports. Load and deflection readings were collected by a data acquisition board and personal computer. Three different techniques were used for measuring the deflections and controlling the test: ram control, load-point control and CMOD control. 
For the case of ram control and load-point control, two linear variable differential transducers (LVDTs) were attached at the load-point locations to a reference bar on one side of the specimen. The reference bar was supported with a pin at mid-depth of the beam over one end support and rested on a smooth pin at mid-depth over the other end support. The two LVDTs made contact with aluminum angles bonded to the surface of the beam under the load-points. Thus the load-point deflection was recorded relative to the neutral axis of the beam. In this system, errors due to extraneous deformations such as seating of the beam and crushing of concrete over the bottom supports are excluded; however crushing of the concrete at the load-points would be included but none was visible during the test. The LVDTs had a sensitivity of $5 \mathrm{mV} / \mathrm{V} / 0.001$ in. The setup can be seen in Fig. 7.

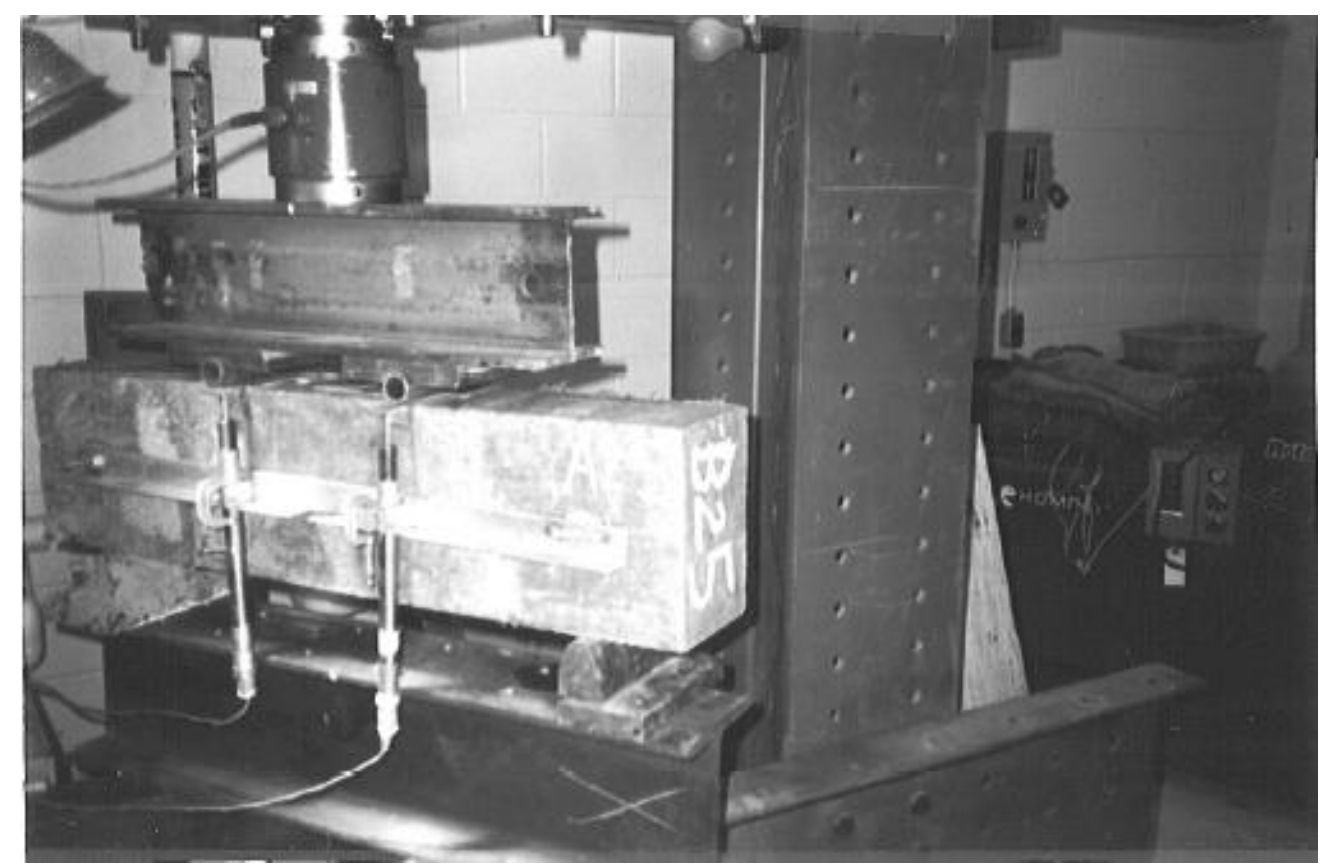

Figure 7. Load-point deflection controlled test.

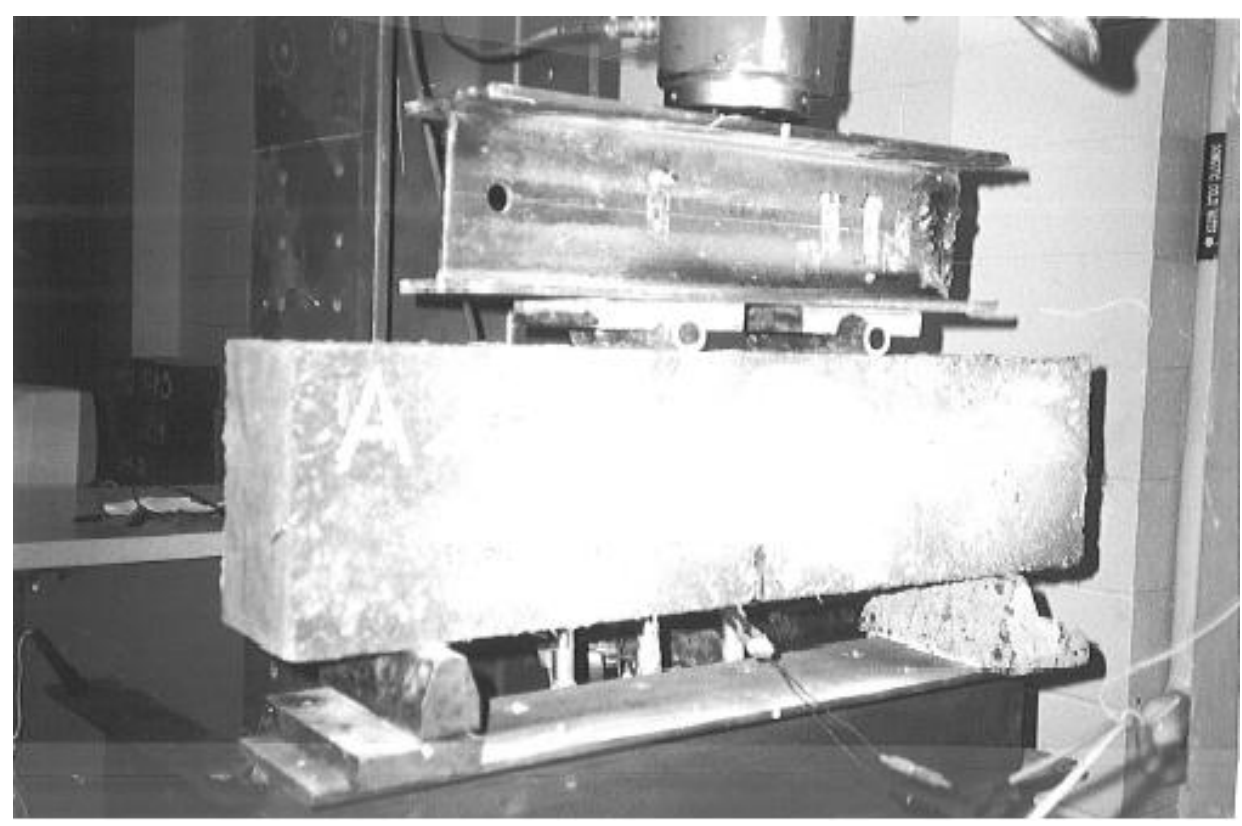

Figure 8. CMOD-controlled tests. 
For the case of ram control, the test was controlled by displacing the actuator (ram) LVDT at a rate of $0.152 \mathrm{~mm} / \mathrm{min}(0.006 \mathrm{in} . / \mathrm{min})$ while the two attached LVDTs measured the load-point deflections passively. For the case of load-point control, the feedback signal that was used to control the test was the average of the two LVDTs mounted to the specimen. The displacement ramp function used was $0.152 \mathrm{~mm} / \mathrm{min}(0.006 \mathrm{in} . / \mathrm{min})$.

In the CMOD control method, a clip gage with sensitivity of $13 \mathrm{mV} / \mathrm{V} / 0.001 \mathrm{in}$. was placed across the mouth of the notch on the underside of the beam. The feedback signal used to control the test was the CMOD at a displacement rate of $0.076 \mathrm{~mm} / \mathrm{min}(0.003 \mathrm{in} . / \mathrm{min})$. The setup can be seen in Fig. 8 .

\section{$4 \quad$ Results}

Some difficulty was encountered in obtaining stable crack propagation in the beams for the ram controlled and load-point deflection controlled experiments. This was particularly problematic in the ram controlled tests. Of the 41 unnotched beams tested, only 13 yielded sufficient post-peak data for the toughness indexes to be calculated. For the tests exhibiting stable failure, the following measures of flexural toughness were able to be calculated: $I_{5}, I_{10}, I_{20}, I_{30}, I_{10} / I_{5}$ ratio, $I_{30} / I_{10}$ ratio, residual strength factors and JSCE toughness index. In contrast, stable crack propagation was achieved for most of the experiments performed using the CMOD control procedure. Out of the 21 notched beams tested, 17 provided sufficient post-peak data to calculate the same flexural toughness indexes mentioned above except that CMOD was used instead of load-point deflection. All of the beams tested provided valid measurements of first crack toughness, first crack deflection or CMOD, first crack strength and flexural strength. The first crack strength was calculated using the load corresponding to the end of the linear portion of the load-deflection or load-CMOD plot, while the flexural strength was calculated using the peak or ultimate load. The stresses were computed using basic elastic analysis.

It could be expected that in order to achieve more stable control from the deflection controlled experiments, the sensitivity of the LVDTs needed to have much higher sensitivity, probably twice as much as the clip gage, which is on the order of $26 \mathrm{mV} / \mathrm{V} / 0.001 \mathrm{in}$. The rationale for this is that CMOD and load-point deflection are geometrically related. For a span/depth ratio of 3 as used in this experiment, the CMOD is twice the vertical displacement measured from the neutral axis to underneath the load-point.

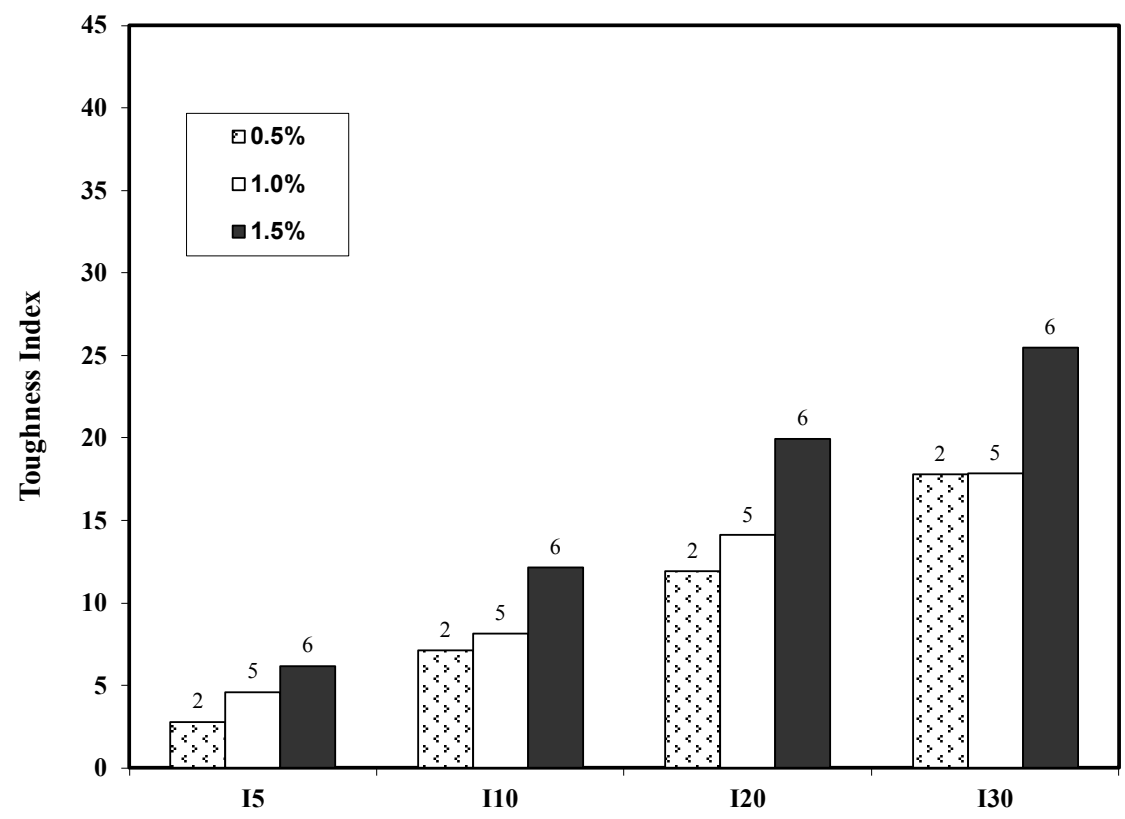

Figure 9. Toughness indexes measured from ram and load-point deflection controlled tests for various fiber volume percentages. Numbers on top of bars indicate the number of specimens. 
ASTM C1018 toughness indexes $\mathrm{I}_{5}, \mathrm{I}_{10}, \mathrm{I}_{20}$ and $\mathrm{I}_{30}$ are shown for the tests using ram control and loadpoint deflection control in Fig. 9. In order to show the sensitivity of the toughness indexes to fiber volume content, the results shown are the average values from combined data for both types of steel fibers and both sizes of beams. In general, the toughness indexes at larger multiples of the first crack deflection, that is $I_{20}$ and $I_{30}$ seem to be better indicators of the improvement in toughness achieved due to fiber reinforcement than $\mathrm{I}_{5}$ and $\mathrm{I}_{10}$. A fiber volume of $1.5 \%$ is effective in improving the toughness, while there appears to be only slight improvement from $0.5 \%$ to $1.0 \%$ volume percentage of fibers.

A similar plot for the ASTM C1018 toughness indexes in terms of CMOD is shown in Fig. 10. To show the effect of fiber volume percentage, the results shown are the average values from combined data for both types of steel fibers and both sizes of notched beams. The toughness indexes $\mathrm{I}_{20}$ and $\mathrm{I}_{30}$ seem to be better than $I_{5}$ and $I_{10}$ for characterizing the toughness of high-strength steel fiber-reinforced concrete. Flexural toughness increases with increasing fiber volume percentage and a volume percentage of $1.5 \%$ is very effective in improving toughness of the high-strength concrete. The results show consistent trends with normal strength (28 MPa) [8, 11] and high-strength (82 MPa) [14] steel fiber-reinforced concrete where it was found that $\mathrm{I}_{5}$ and $\mathrm{I}_{10}$ were insensitive to fiber volume content.

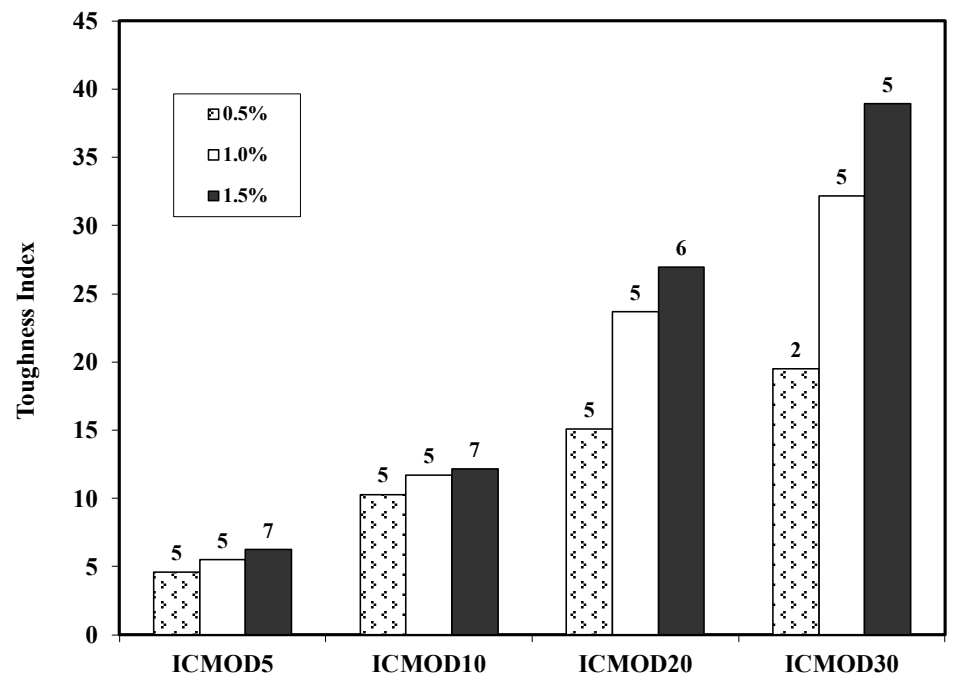

Figure 10. Toughness indexes measured from CMOD controlled tests for various fiber volume percentages.

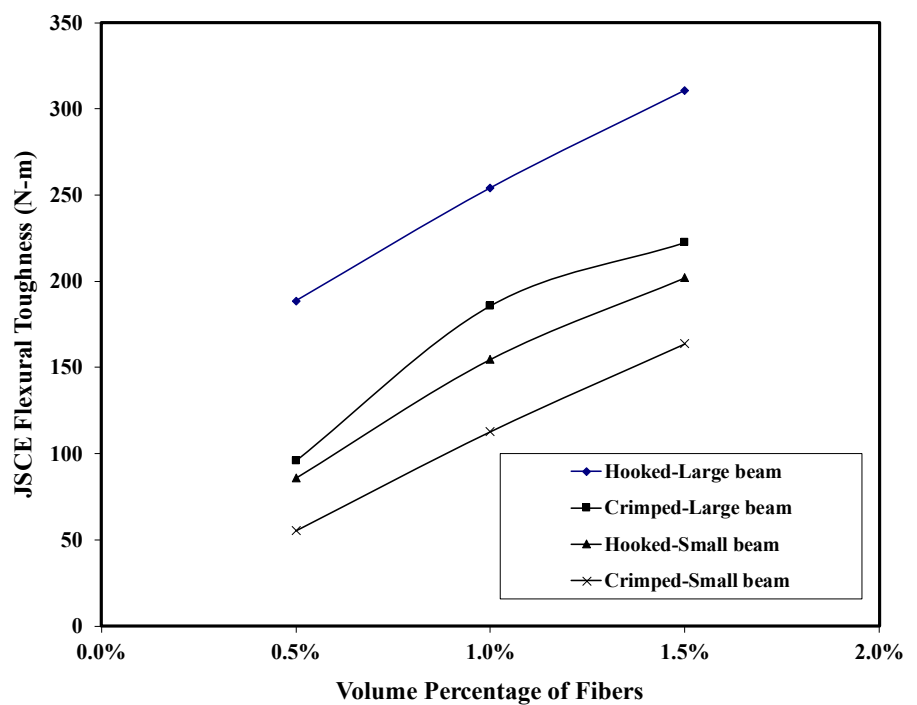

Figure 11. JSCE flexural toughness index as a function of fiber volume percentage. Values are shown for hooked and crimped fibers in both large and small beam sizes. 
The values for the JSCE toughness index calculated from CMOD controlled tests are shown in Fig. 11. The JSCE index which is an absolute rather than a relative toughness measure seems to be a better indicator for evaluating toughness improvement with varying fiber volume percentages. The toughness index increases with increasing fiber volume percentage. The results also show that hooked-end fibers are more effective than crimped fiber in providing added flexural toughness. The results also indicate an apparent size effect in the flexural toughness measurement with larger beams giving higher toughness values. A similar finding that JSCE toughness index increased with increasing specimen depth was reported for normal strength $(28 \mathrm{MPa})$ steel fiber-reinforced concrete [11].

The flexural strength obtained from ram and load-point deflection controlled tests is shown in Fig. 12 and the flexural strength obtained from CMOD tests is shown in Fig. 13. The results show an increase in the flexural strength with increasing fiber volume percentages. The hooked-end fibers provide higher flexural strength than the crimped fibers. A size effect appears to exist in the flexural strength measurements with the smaller sized beams yielding larger values of flexural strength.

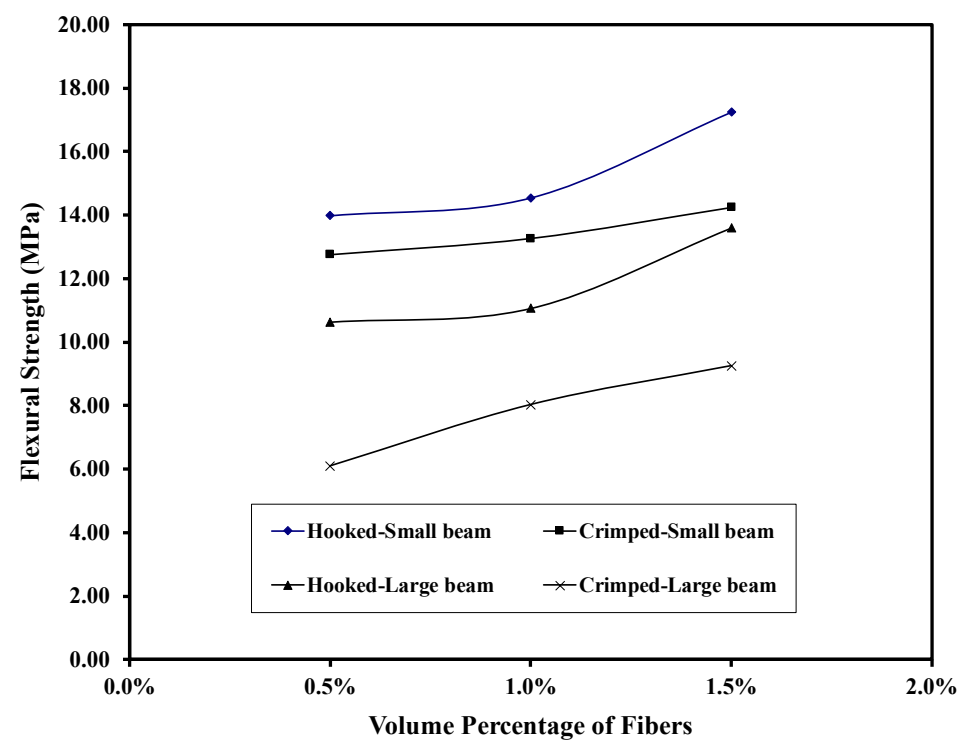

Figure 12. Flexural strength measured from ram and load-point deflection controlled tests as a function of fiber volume percentage. Values are shown for hooked and crimped fibers in both large and small beam sizes.

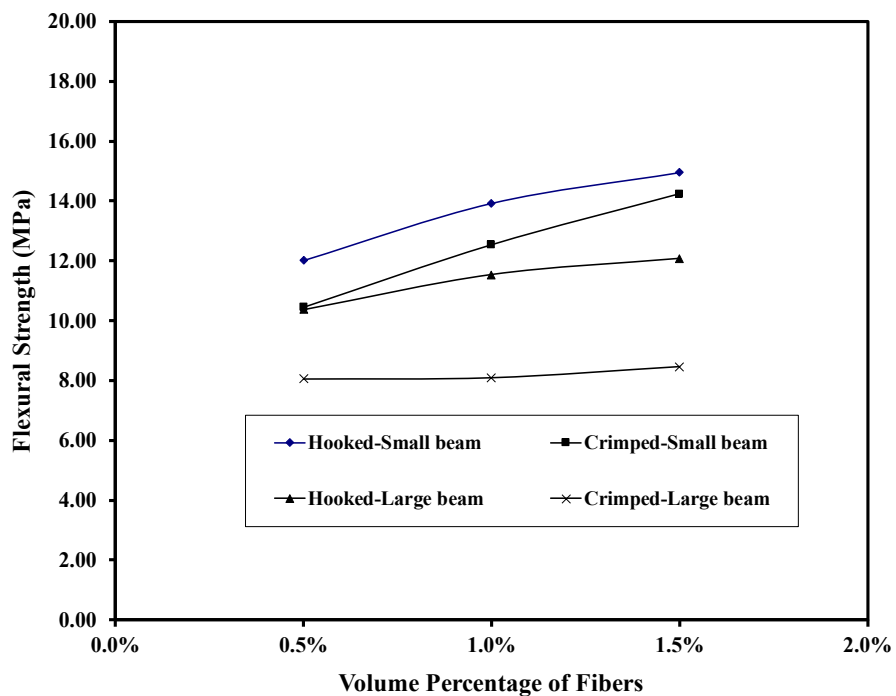

Figure 13. Flexural strength measured from CMOD controlled tests as a function of fiber volume percentage. Values are shown for hooked and crimped fibers in both large and small beam sizes. 
The first-crack strength obtained from ram and load-point deflection controlled tests is shown in Fig. 14 and the first-crack strength from CMOD tests is shown in Fig. 15. The results show an increase in the first-crack strength with increasing fiber volume percentages. The hooked-end fibers provide higher first-crack strength than the crimped fibers. The first-crack strength appears to decrease somewhat with specimen size both for the unnotched and the notched beams. This apparent size effect on the first-crack strength has also been noted for normal strength (28 MPa) steel fiber-reinforced concrete [11].

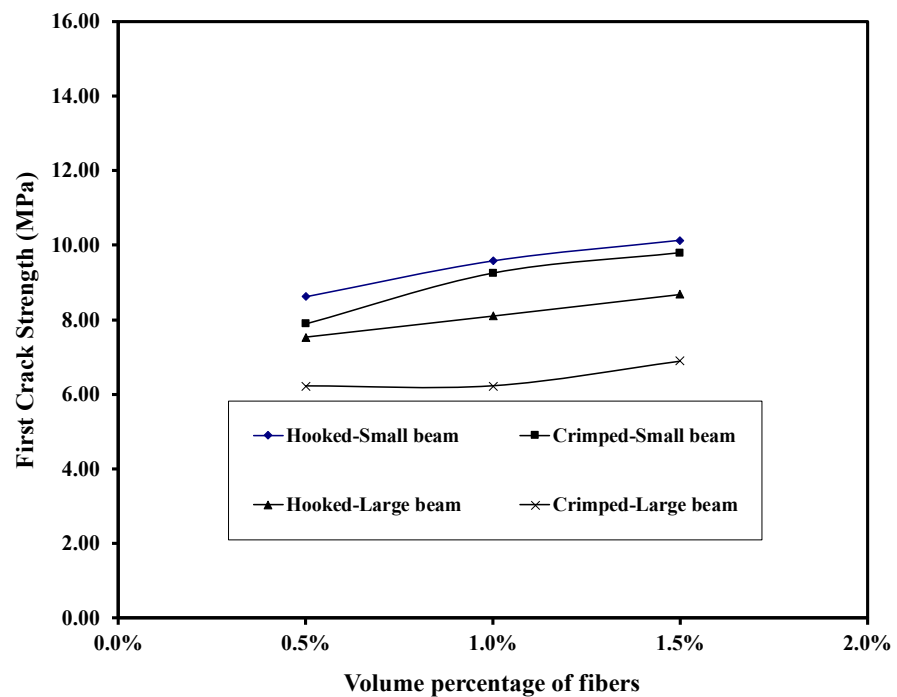

Figure 14. First crack strength measured from load-point deflection controlled tests as a function of fiber volume percentage. Values are shown for hooked and crimped fibers in both large and small beam sizes.

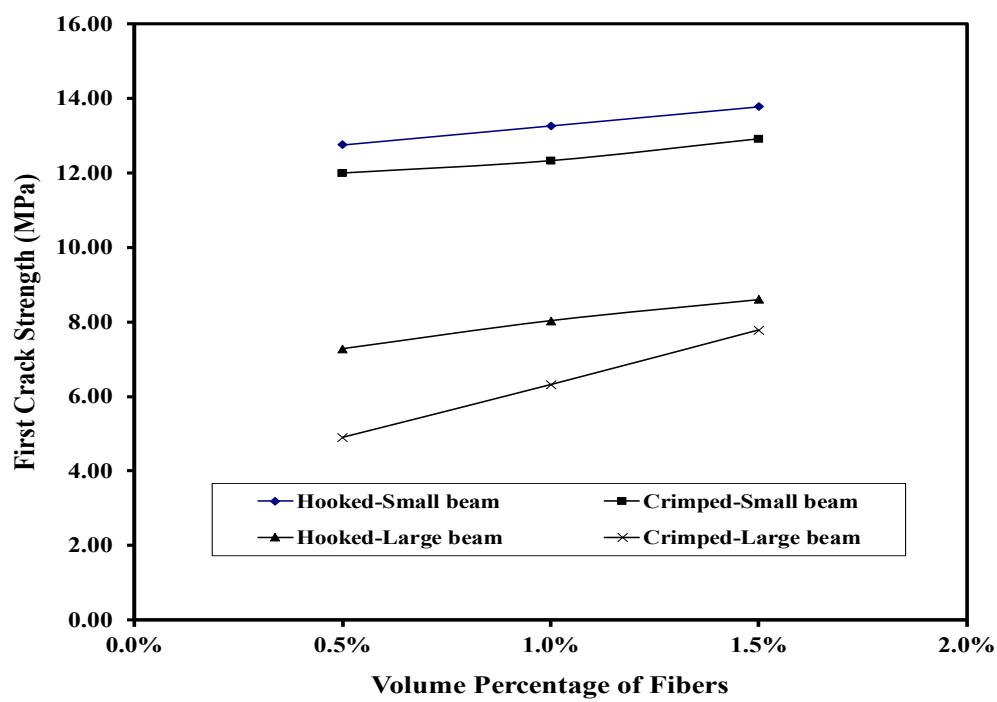

Figure 15. First crack strength measured from CMOD controlled tests as a function of fiber volume percentage. Values are shown for hooked and crimped fibers in both large and small beam sizes.

The mechanism of fiber contribution to bending resistance and ductility is explained as follows. At lower load levels, the stress and strain distribution can be assumed to be linear. When the maximum tension stress reaches the tensile strength of the matrix, it cracks and this changes the stress distribution considerably. When the matrix cracks, the load carried by the matrix is transferred to the fibers. The more the number of fibers bridging the crack, the more resistance can be provided and loadsoftening behavior can be obtained. For very high fiber contents, load-hardening response can be obtained but this is not usually practical for field applications. Thus for a given fiber type, a higher 
volume fraction should provide more toughness as long as the fibers can be properly mixed and the composite can be cast and compacted properly. In addition, the amount of force that can be sustained by a fiber bridging a crack depends on its strength and the bond between fiber and matrix. Thus, the fiber can provide continued resistance until it either breaks or pulls out. The results of this study showed that fibers with end anchorage in the form of hooks tended to give superior performance than deformed (crimped) fiber in most respects. This is most likely due to better pullout resistance. The matrix composition is also important in terms of its bond characteristics with the fibers and its brittleness. More brittle composites will require larger amounts of fiber to achieve ductility. The brittleness of the matrix is directly related to the compressive strength. The results of this study show that a fiber volume percentage of $1.5 \%$ was quite effective in improving the toughness of high-strength concrete.

Analysis of variance (ANOVA) was performed for the entire set of data including all test methods. The results for the effect of fiber volume can be seen in Table 2. The properties are presented in order of increasing $p$-value. An $F$ statistic greater than $F_{\text {crit }}$ indicates that there is an effect of fiber volume on that property. It can be clearly seen that the JSCE toughness index is the most sensitive to the fiber volume, while I5 and flexural strength can also be considered to be affected by fiber volume at the $\alpha=$ 0.05 significance level. By observing the $p$-value, it can be seen that at a significance level of $\alpha=0.10$, most of the measures would be sensitive to fiber volume. The ANOVA results for the effect of beam size can be seen in Table 3. The flexural strength can be seen to be affected by beam size; however, the toughness is not. The ANOVA results for the effect of type of fiber can be seen in Table 4. Hooked fibers provided higher flexural strength and toughness than crimped fibers but the effect on toughness was not significant at the $\alpha=0.05$ level.

Table 2. ANOVA Results for Effect of Fiber Volume (3 levels, $\alpha=0.05$ ).

\begin{tabular}{cccccccccc}
\hline Property: & $\begin{array}{c}\text { JSCE } \\
\text { Index }\end{array}$ & I5 & $\begin{array}{c}\text { Flexural } \\
\text { Strength }\end{array}$ & I10/I5 & $\begin{array}{c}\text { 1st Crack } \\
\text { Toughness }\end{array}$ & $\begin{array}{c}\text { 1st Crack } \\
\text { Deflection }\end{array}$ & I20 & I30 & I10 \\
\hline $0.5 \%$ Count & 6 & 6 & 19 & 6 & 19 & 19 & 6 & 2 & 6 \\
1.0\% Count & 10 & 10 & 23 & 10 & 23 & 23 & 10 & 10 & 10 \\
1.5\% Count & 13 & 13 & 20 & 13 & 20 & 20 & 12 & 11 & 13 \\
0.5\% Mean & 0.790 & 4.28 & 1510.9 & 2.35 & 47.58 & 0.00553 & 18.58 & 16.45 & 9.77 \\
1.0\% Mean & 1.12 & 5.43 & 1623.1 & 1.87 & 59.00 & 0.00681 & 17.80 & 25.00 & 10.16 \\
$1.5 \%$ Mean & 1.91 & 5.83 & 1850.6 & 2.06 & 182.28 & 0.01930 & 23.45 & 31.57 & 11.92 \\
0.5\% Var. & 0.174 & 2.01 & 178821 & 0.28 & 1367.0 & 0.00001 & 32.39 & 3.65 & 7.75 \\
$1.0 \%$ Var. & 0.119 & 1.55 & 150844 & 0.07 & 5125.5 & 0.00004 & 42.77 & 88.60 & 6.76 \\
$1.5 \%$ Var. & 0.305 & 0.852 & 240027 & 0.12 & 113527 & 0.00122 & 40.20 & 126.63 & 5.22 \\
F & 14.95 & 3.75 & 3.14 & 3.21 & 2.89 & 2.85 & 2.52 & 2.37 & 2.15 \\
P-Value & 0.00 & 0.04 & 0.05 & 0.06 & 0.06 & 0.07 & 0.10 & 0.12 & 0.14 \\
F & 3.37 & 3.37 & 3.15 & 3.37 & 3.15 & 3.15 & 3.39 & 3.49 & 3.37 \\
\hline
\end{tabular}

Table 3. ANOVA Results for Beam Size (2 levels, $\square=0.05$ ).

\begin{tabular}{ccc}
\hline Property: & Flexural Strength & JSCE Index \\
\hline Large Count & 41 & 12 \\
Medium Count & 21 & 17 \\
Large Mean & 1510.9 & 1.46 \\
Medium Mean & 1957.3 & 1.38 \\
Large Variance & 87366 & 0.42 \\
Medium Variance & 300818 & 0.46 \\
F & 17.45 & 0.10 \\
P-Value & 0.00 & 0.75 \\
F $_{\text {crit }}$ & 4.00 & 4.21 \\
\hline
\end{tabular}


Table 4. ANOVA Results for Fiber Type (2 levels, $\alpha=0.05)$.

\begin{tabular}{ccc}
\hline Property: & Flexural Strength & JSCE Index \\
\hline Crimped Count & 30 & 16 \\
Hooked Count & 32 & 13 \\
Crimped Mean & 1515.0 & 1.23 \\
Hooked Mean & 1800.1 & 1.63 \\
Crimped Variance & 253022 & 0.27 \\
Hooked Variance & 118763 & 0.58 \\
F & 6.85 & 2.74 \\
P-Value & 0.01 & 0.11 \\
F $_{\text {crit }}$ & 4.00 & 4.21 \\
\hline
\end{tabular}

\section{Conclusions}

Flexural strength and toughness measurements were made on two sizes of both notched and unnotched beams of high-strength $(103 \mathrm{MPa})$ concrete reinforced with steel fiber. Hooked-end and crimped fibers were studied and the volume percentage of fibers was varied between $0.5 \%, 1.0 \%$ and $1.5 \%$. Three different techniques for controlling the experiments were tried namely ram displacement control, loadpoint deflection control and crack mouth opening displacement control.

CMOD control method was found to provide the most stable crack growth and is recommended for the testing of the relatively brittle high-strength concrete. The CMOD is less prone to the errors that can easily affect deflection measurements. The $\mathrm{I}_{5}, \mathrm{I}_{10}, \mathrm{I}_{\text {CMOD5 }}$ and $\mathrm{I}_{\text {CMOD10 }}$ fracture toughness values were relatively insensitive in distinguishing fiber performance. The $\mathrm{I}_{20}, \mathrm{I}_{30}, \mathrm{I}_{\mathrm{CMOD} 20}$ and $\mathrm{I}_{\mathrm{CMOD} 30}$ values exhibited greater sensitivity to fiber volume and fiber type than $I_{5}$ and $I_{10}$ values. The JSCE toughness index which is an absolute measure of toughness increased with fiber volume percentage and beam size for both types of fibers. The JSCE index is better than the ASTM C1018 procedure in distinguishing the difference in performance due to varying fiber volume percentages. From experimental observations, the fracture of high-strength concrete was dominated by fiber pullout rather than fracture. The hooked-end fibers seemed to be superior to the crimped fibers in increasing the flexural toughness, flexural strength, and first-crack strength of the composite. An apparent size effect appears to exist as smaller beams tended to give larger values of first-crack strength and flexural strength than the larger beams. The addition of steel fibers to the brittle high-strength concrete can be effective in improving the ductility of the composite particularly at a dosage rate of $1.5 \%$. The resulting concrete mixture at such a high volume percentage of fibers was found to have suitable workability and the fibers could be mixed properly and the composite consolidated effectively.

Acknowledgments. The author gratefully acknowledges the support of the following companies for their donation of materials to the research program: Lafarge Corporation of Southfield, Michigan who supplied the fly ash; Globe Metallurgical Inc., of Niagara Falls, N.Y., who supplied the silica fume; and Master Builders Technologies of Cleveland, Ohio, who supplied the high-range water-reducing admixture.

\section{References}

1. ACI Committee 544, State of the Art Report on Fiber-Reinforced Concrete, American Concrete Institute, Farmington Hills, Mich., 1989.

2. V. S. Gopalaratnam, and R. Gettu, "On the characterization of flexural toughness in fiber-reinforced concretes," Cement \& Concrete Composites, vol. 17, pp. 239-254, 1995.

3. American Society for Testing and Materials (ASTM), Standard Test Method for Flexural Toughness and First Crack Strength of Fiber-Reinforced Concrete (Using Beam with Third-Point Loading), American Society for Testing and Materials, ASTM C1018-97, Philadelphia, Pa., 2001. 
4. American Society for Testing and Materials (ASTM), Standard Test Method for Flexural Strength of Concrete (Using Simple Beam with Third-Point Loading), American Society for Testing and Materials, ASTM C78-00, Philadelphia, Pa., 2001.

5. American Society for Testing and Materials (ASTM), Standard Test Method for Flexural Performance of FiberReinforced Concrete (Using Beam with Third-Point Loading), American Society for Testing and Materials, ASTM C1609-12, Philadelphia, Pa., 2017.

6. Japan Society of Civil Engineers (JSCE), Method of Test for Flexural Strength and Flexural Toughness of FiberReinforced Concrete, Standard SF-4, Japan Society of Civil Engineers, Tokyo, 1984.

7. ACI Committee 544, Measurement of Properties of Fiber-Reinforced Concrete, American Concrete Institute, Farmington Hills, Mich., 1989.

8. P. N. Balaguru, and S. P. Shah, Fiber-Reinforced Cement Composites, McGraw-Hill, New York, New York, 1992.

9. N. Banthia, and J. F. Trottier, "Test methods for flexural toughness characterization of fiber reinforced concrete: some concerns and a proposition," ACI Materials Journal, vol. 92, no. 1, pp. 1-10, 1995.

10. S.T. Islam, Study of Some Parameters Affecting the Measured Flexural Toughness of Fiber Reinforced Concrete, Master's Thesis, University of British Columbia, Vancouver, 2012.

11. V. Gopalaratnam, S.P. Shah, G. B. Batson, M. Criswell, V. Ramakrishnan, and M. Wecharatana, "Fracture toughness of fiber reinforced concrete," ACI Materials Journal, vol. 88, no. 4, pp. 339-353, 1991.

12. N. Banthia, and A. Dubey, "Measurement of flexural toughness of fiber-reinforced concrete using a novel technique - part 1: assessment and calibration," ACI Materials Journal, vol. 96, no. 6, pp. 651-657, 1999.

13. P. Soroushian, and Z. Bayasi, "Fiber-type effects on the performance of steel fiber reinforced concrete," ACI Materials Journal, vol. 88, no. 2, pp. 129-134, 1991.

14. P. Balaguru, R. Narahari, and M. Patel, "Flexural toughness of steel fiber reinforced concrete," ACI Materials Journal, vol. 89, no. 6, pp. 541-546, 1992.

15. Q. Chunxiang, and I. Patnaikuni, "Properties of high-strength steel fiber-reinforced concrete beams in bending," Cement and Concrete Composites, vol. 21, pp. 73-81, 1999. 